\title{
EGFR NP_005219.2:p.C797S
}

National Cancer Institute

\section{Source}

National Cancer Institute. EGFR NP 005219.2:p.C797S. NCI Thesaurus. Code C147011.

A change in the amino acid residue at position 797 in the epidermal growth factor receptor protein where cysteine has been replaced by serine. 